\title{
Run by the local undergraduate electricity class specialized in "university-enterprise cooperation and work-integrated learning" practice and exploration
}

\author{
Haiyan wang ${ }^{1, a}$, Xuejun $\mathrm{Li}^{1, \mathrm{~b}}$ and Congbo Luo ${ }^{1, \mathrm{c}}$ \\ ${ }^{1}$ Changchun University of science and technology, changchun 130000, China; \\ A13742883@qq.com, b609872165@qq.com, 'c43403188@qq.com
}

Keywords: Run by the localundergraduate ,Electricityclassspecialized ,University-enterprise cooperation, Teaching mode,Work-integrated learning.

\begin{abstract}
. along with our country socialist construction with each passing day, the electronics industry is developing at a surprising speed, cause the employer to graduates of quality and quantity of the demand is higher and higher. In order to reduce the gap between the professional quality of graduates and enterprise requirements, adapt to the enterprise continuously updated standard of choose and employ persons, to carry out the "university-enterprise cooperation and work-integrated learning" is the necessary way of universities, this article according to the actual situation of the electricity speciality in combination with the current private higher school personnel training problems, discussion and work out concrete cooperation between colleges and the practice of work-integrated learning scheme.
\end{abstract}

\section{Introduction}

At present, the role of private higher education in higher education is more and more important, is an indispensable part of its, state of private higher education is more and more attention. Private higher education can make the workers get effective fast to improve professional ability, along with the advance of science and technology enterprise needs and requirements to the person also is changing, non-governmental institutions of higher learning society, and enterprise standards in order to keep reforming teaching methods, to adapt to the development of vocational education reform. Our existing electronic information science and technology, measurement and control technology and instrument and automation three electricity class specialized, in order to strengthen the students' practice teaching, improve the skill levels of students, make students obtain employment, we put forward the university-enterprise cooperation and work-integrated learning personnel training mode, cooperate with the enterprise, to explore educational ways and methods, enterprises, schools, students, and win-win is realized. But, in the current "university-enterprise cooperation and work-integrated learning", there are a lot of problems in our hospital combined with several years of working experience in teaching, on the basis of the practice teaching of "university-enterprise cooperation and work-integrated learning" teaching mode has made the certain research, and formulate the concrete detailed rules for the implementation of the plan.

\section{"university-enterprise cooperation and work-integrated learning" the purpose and significance}

In university-enterprise cooperation and work-integrated learning the teaching way, broke the previous set by the university itself independent practice the talent training scheme. The introduction of advanced enterprise concept to make enterprises to participate in, to jointly with the school in teaching training high skills, high quality talent. To cultivate the students' professional skills, improve the students' professional quality, reduce the economic burden of students, and solves the problem of colleges and universities cultivate talent and enterprise of derailment. 
First of all, university-enterprise cooperation and work-integrated learning mode for cultivating the students' vocational skills, can make the electricity class specialized student to work for a real company, work experience, enhance the competitiveness of their employment.

At present, all employers want there are both profound theoretical basis and skilled operation experience of talent. If the student has been less than corporate internship training in the college, could not get work experience, also won't meet the standard of choose and employ persons of the enterprise. If the university-enterprise cooperation and work-integrated learning mode of teaching, the school students into the relevant enterprises, carried out in accordance with the unit of real production and services required to participate in work practice, obtain in the true sense of practical work experience. It's only make up for the graduates lack of theoretical knowledge and the lack of work experience.

Secondly, university-enterprise cooperation and work-integrated learning teaching model can effectively improve the students' professional quality, smooth transition. College students, is actually a from the practical work of students, to enterprise's work in the dark. When students enter the enterprise practice, students and enterprise employees, equal pay for equal work is a real sense of employee. The benefit of the influence of the corporate culture, bears hardships and stands hard work, wuxi, enhance feelings for jobs and career.

Again, the teaching mode of university-enterprise cooperation and work-integrated learning enables students to position themselves accurately, timely grasp employment information, realize the students employment and enterprise employee smooth docking. Students can not only obtain the enterprise internship phase specific ability exercise, can understand general enterprise in the daily work on the talent requirements. For effective and information. Through this kind of cooperation mode at the same time, schools also can accurately grasp the development trend of electricity industry, adjust the teaching contents, produce more competitive talents.

\section{Run by the local undergraduate electricity class specialized "university-enterprise cooperation and work-integrated learning" the status quo}

Since China launched the "university-enterprise cooperation and work-integrated learning" mode, the current are actively carry out most of the colleges and universities. Many colleges and universities to do investigation and study, not blindly sign a contract with the enterprise, according to the requirements of enterprise training talents train, there is a certain problem: first, the school has long been a teaching unit, which the talent training scheme, teaching plan, establishment of curriculum system should be after a long discussion, at the same time, school teachers and teaching facilities is also not easy to change. This restricted the pace of the school, can't sync with the enterprise.

Second, the enterprise does not accept this model. Many companies don't accept private colleges students, poor thought to underlie the students of the colleges and universities, poor foundation, learning ability is insufficient, in the enterprise practice will not only bring economic benefits for enterprises but also disturbs the enterprise normal production order. Rather than admit vestibule school students, also don't accept private undergraduate students. Third, the government did not provide favorable conditions for such cooperation, and guarantee system. Universities and colleges in the university-enterprise cooperation is the school to contact the internship units or through intermediaries, units on the lack of guidance and supervision of cooperation are prone to all kinds of problems. Easy no constraint to the enterprise fails to perform the enterprise to the student's responsibility, no constraint is easy to cause the students to the student internship to the prescribed time limit according to the contract, to the enterprise caused economic losses. This will lead to the development of this cooperation pattern is not healthy. 


\section{Electricity class specialized "university-enterprise cooperation and work-integrated learning" teaching mode}

1." $3+1$ " revision of the talent training scheme. Our electricity class three major for undergraduate programs, four years of schooling. In order to better implement the university-enterprise cooperation, the combination of learning mode, our hospital has implemented the " $3+1$ " training mode. The theory of learning in school for three years, last year to take part in practice. This provides ample practice time, provides the university-enterprise cooperation and work-integrated learning time guarantee.

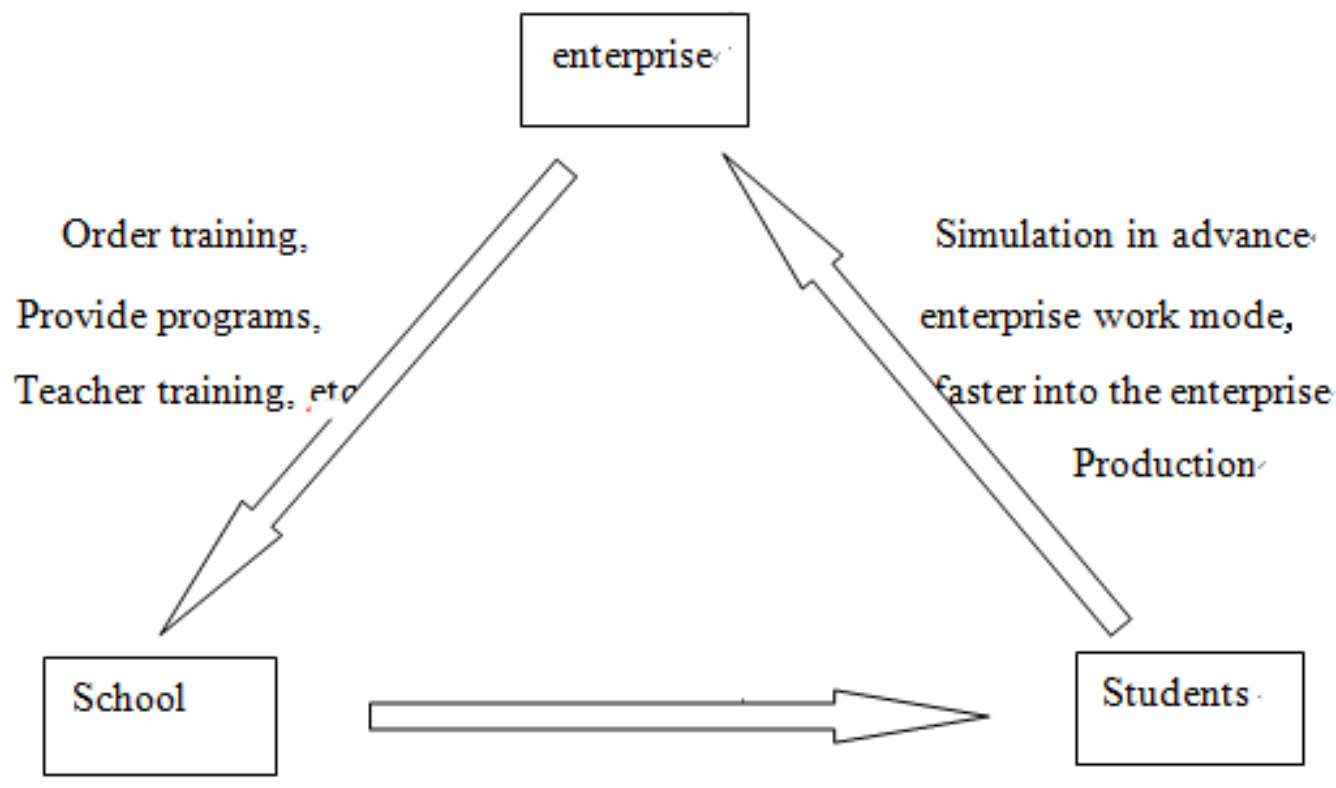

Professional reform, according to the need to develop

2. combining enterprise modify teaching plan, the implementation of ordering teaching training. Past our electrical professional teaching plan strictly implement the requirements of ministry of education, mainly theoretical study, most of the time theory study at school, only arrange short visit in individual semester internship, etc. In order to achieve the cooperation between colleges and work-integrated learning teaching mode, we redesign the teaching plan. After school and study of related companies, identifying the agreement of cooperation in running schools. Schools can according to the requirement of the cooperative unit, revising the talent training scheme, teaching plan and curriculum plan, and invited famous experts to participate in teaching together, for the cultivation of the students in specialized, orientation. Students learn over qualified after graduation, according to the agreement enterprises automatically receive graduates.

3. improve teachers' practical ability, and enterprise standards. Our current state of teachers tend to be younger, young teachers' teaching enthusiasm, but the lack of certain practical teaching experience. To produce outstanding graduates, first of all our teachers to ascend. Every year our hospital in a planned way to arrange some young teachers into the cooperative enterprises to participate in the production practice, master the enterprise specific jobs demand for skills, participation enterprise technical updating and transformation, understand the enterprise technology development prospects. Through the communication, teachers' professional skills and practical teaching ability has been greatly improved. At the same time the enterprise excellent experts came to the school to parents, to reduce the gap between school and enterprise, to speed up the school and enterprises "integration" the construction of teachers team. 
To create a new practical teaching system. Since our proposed that the " $3+1 "$ training mode, practice teaching attaches great

Importance to the whole senior year. College of information engineering school of electricity class specialized practice teaching link by five weeks of the school of training in the school and outside school for a period of 20 weeks practice outside of two modes. School training in half semester of senior year, the institute will organize special training teacher to student training exercises. Training program that is associated with enterprise production, the purpose is to consolidate students' theoretical knowledge and practice to lay a solid foundation for the enterprise. Off-campus internship are classified into practice, training, and create positions practice three categories. First of all, it is a short-term trainee to visit internship, teachers lead students to the relevant enterprises to visit, full-time personnel responsible for the interpretation by the enterprise, make the students understand the enterprise, understand the production process of enterprises and production line equipment principle of work, learning from the apprentice to the enterprise all aspects of culture, real experience to the enterprise's production and life. Second, the enterprise training is to point to send students to do some learning expertise, this requires students to the enterprise to pay a certain amount of training fees, after the enterprise is responsible for training arrangements employment, both parties need to identify the contract. In the end, is the enterprise according to their own requirements to create positions internship school through interview and basic skills assessment, choose what you need interns. To the enterprise field work, is the enterprise production workshop as practical classroom teaching, students realize zero distance contact with enterprise. Middle school students in the enterprise and enterprise employees equal pay for equal work, have a fixed position, to get a fixed salary. Pave the way for future employment.






\section{Conclusion}

I three electricity class specialized information engineering college of university-enterprise cooperation and work-integrated learning teaching mode, although have already begun to take shape but also has certain problem, need to be further strengthened. Our next plan to let teachers lead students to the enterprise for production and processing, the specialized training for teachers to enterprises, but also provides training and continuing education workers, conditional and set up a joint enterprise school-run factory. Vision, strengthen "university-enterprise cooperation and work-integrated learning", will build platform of employment, more students to more enterprises directly deliver more excellent talents of high quality, high skills, also can better realize the sustainable development of the school!

\section{References}

[1] c-ray-z Liu Yanlin. Cooperation between higher vocational colleges and the mode of high vocational education practice curriculum plan to explore - environment classes, for example [J]. Journal of shenzhen institute of information technology, 2013, 2013:47-50.

[2] zhang hong. Explore the "work-integrated learning and cooperation between higher vocational colleges to cultivate professional talents [J]. Chinese science and education innovation Tribune, 2013, 31:4.

[3] ya-ming wang. Our country secondary vocational university-enterprise cooperation research review [J]. Journal of continuing education research, 2013, 10:37, 39.

[4] xiao jing. Vestibule school "work-integrated learning" cultivation mode of practice research [D]. Hunan university, 2013

[5] li-ling hu. Co-operative personnel training mode of higher vocational education research [D]. Fujian normal university, 2010.

[6] becky. $\mathrm{N}$ the metro rail transit based on university-enterprise cooperation professional personnel training mode research [D]. Dalian maritime university, 2012.

[7] Fang Daichun. Higher vocational university-enterprise cooperation "2 + 1" training mode of practice research [D]. East China normal university, 2008 